\title{
Vector Autoregressive (VAR) Modeling and Projection of DSE
}

\author{
Ahammad Hossain \\ Varendra University, Rajshahi, Bangladesh \\ Md. Kamruzzaman, Md. Ayub Ali \\ University of Rajshahi, Rajshahi, Bangladesh
}

\begin{abstract}
In this paper, vector autoregressive (VAR) models have been recognized for the selected indicators of Dhaka stock exchange (DSE). Bangladesh uses the micro economic variables, such as stock trade, invested stock capital, stock volume, current market value, and DSE general indexes which have the direct impact on DSE prices. The data were collected for the period from June 2004 to July 2013 as the basis on daily scale. But to get the maximum explorative information and reduction of volatility, the data have been transformed to the monthly scale. The outliers and extreme values of the study variables are detected through box and whisker plot. To detect the unit root property of the study variables, various unit root tests have been applied. The forecast performance of the different VAR models is compared to have the minimum residual. Moreover, the dynamics of this financial market is analyzed through Granger causality and impulse response analysis.
\end{abstract}

Keywords: vector autoregressive (VAR) model, impulse response analysis, Granger causality

\section{Introduction}

Dhaka stock exchange (DSE) functions as a strong mechanism in the industrialization and economic growth of Bangladesh. The development of the capital market is essential for capital accumulation, efficient distribution of recourses, and promotion of economic growth. There is no doubt that a vibrant capital market is likely to support economy to be robust, but two major catastrophes in the capital market of Bangladesh within one and half decades do not indicate the existence of a vibrant market; rather these show a highly risky and unstable capital market. The recent surge in the capital market has shaken the whole country, as millions of people became insolvent within a very short span of time. It was observed in 2010 that the DSE general index was the highest ever, which made it Asia's top performer after China (Islam, 2011), while the reverse scenario was scaring investors in the first quarter of 2011, as the lowest ever in the index observed during that period. Modeling the dynamics of stock markets is gaining popularity among researchers, because of theoretical and technical reasons. Economic agents, both private and public, have close interest with the movements of the stock market index, stock trade, invested stock capital, stock volume interest rates, and exchange rates in order to make investment and economic policy decisions. Therefore, building efficient forecasting models for these variables plays important roles in the decision-making processes. Although, univariate models ARMA $(p, q)$

Ahammad Hossain, M.Sc., lecturer, Department of Natural Science, Varendra University, Rajshahi, Bangladesh.

Md. Kamruzzaman, Ph.D., associate professor, Institute of Bangladesh Studies, University of Rajshahi, Rajshahi, Bangladesh. Md. Ayub Ali, Ph.D., professor, Department of Statistics, University of Rajshahi, Rajshahi, Bangladesh.

Correspondence concerning this article should be addressed to Ahammad Hossain, Department of Natural Science, Varendra University, 529/1, Kazla, Motihar, Rajshahi-6204, Bangladesh. E-mail: ahammadstatru@gmail.com. 
and $\operatorname{GARCH}(p, q)$ are widely used in the literature by the researchers for modeling and forecasting purposes, there is a very little study about multivariate modeling. So, it is also important to analyze the interaction among variables in a multivariate framework. In this paper, authors move forward into this procedure by applying vector autoregressive (VAR) models in modeling the financial variables of DSE.

\section{Objectives of Study}

The main objectives of this paper are:

- to explore summary statistics of the study variables which have the most rational impact on the portfolios of DSE prices;

- to check the stationary condition of study variables;

- to propose VAR models on stock indicators;

- to apply appropriate criteria for model selection;

- to provide test of statistical hypothesis for model adequacy and stability;

- to apply statistical tests on estimated residual for model diagnostics;

- to show the forecasting performance of the proposed model;

- to carry out suggestions and policy implications.

\section{Literature Review}

In recent years, many market analysts have started arguing for market inefficiency at least for its weak form. They claim that the traders are now paying more attention to the information which is related to recent trends in return instead of putting emphasis on the information which is related to future dividends. A large number of traders are buying stocks, only because past returns were very high. These traders are often called feedback traders; they believe that if the stock returns were high in the recent past, they are likely to be high in future. Such behaviors of traders cause stock prices to go beyond the true values of stocks in the short run (Khababa, 1998). This feedback trading makes the market more volatile in the short run, because in the long run, the stock prices tend to return to their true values. In respect of weak form efficiency of DSE, some researchers have done several works (Uddin \& Khoda, 2009; Mobarek, Mollah, \& Bhuyan, 2008; Hassan \& Chowdhury, 2008; Uddin \& Alam, 2007; Ainul \& Khaled, 2005; Kader \& Rahman, 2005; Sadique \& Chowdhury, 2002; Koutmos, Negakis, \& Theodossiou, 1993; Chowdhury, Sadique, \& Rahman, 2001). But, it is rare in conducting VAR model in order to find the relationship between risk and return of DSE. The VAR model is one of the most successful, flexible, and easy models for the analysis of multivariate time series. VAR models in economics were made popular by Sims (1980). It is a natural extension of the univariate autoregressive model. The VAR model is useful for describing the dynamic behavior of financial time series and for forecasting. The superior forecasts to those from univariate time series models and elaborate theory-based simultaneous equations models can be provided by using VAR models. Forecasting is quite flexible, since they can be made conditional on the potential future paths of specified variables in the model. There are many studies about modeling financial time series with VAR models. The most important one is the book of Culbertson (1996) that is about stocks, bonds, and foreign exchange. But there are a few studies about Bangladeshi financial market especially in the period which includes in 2011 to 2013 financial crises. In addition to data description and forecasting, the VAR model is also used for structural inference and policy analysis. In structural analysis, certain assumptions about the causal structure of the data under investigation are imposed and the resulting causal impacts of unexpected shocks or innovations to specified variables on the 
variables in the model are summarized. These causal impacts are usually summarized with impulse response functions and forecast error variance decompositions. The definitive technical reference for VAR models is Lutkepohl (1991) and updated surveys of VAR techniques are given in works of Watson (1994); Lutkepohl (1999); and Waggoner and Zha (1999). Applications of VAR models to financial data are given in works of Hamilton (1994a; 1994b); Campbell, Lo, and MacKinlay (1997); Mills (1999); and Tsay (2001).

\section{Methodology}

\section{Stationary Time Series}

A series is said to be (weakly or covariance) stationary, if the mean and auto covariance of the series do not depend on time. Any series that is not stationary is said to be non-stationary. A common example of a non-stationary series is the random walk:

$$
Y_{t}=Y_{t-1}+\varepsilon_{t}
$$

where, $\varepsilon_{t}$ is a stationary random disturbance term; the series $Y_{t}$ has a constant forecast value, conditional on $t$; and the variance is increasing over time. Augmented Dickey-Fuller (ADF) (Dickey \& Fuller, 1979), Phillips-Perron test (PP) (Phillips \& Perron, 1998), GLS detrended Dickey-Fuller (ERS) (Elliott, Rothenberg, \& Stock, 1996), KPSS (Kwiatkowski, Phillips, Schmidt, \& Shin, 1992), and Ng-Perron tests (NP) (Ng \& Perron, 2001) are recognized as unit root tests for a time series to be stationary or not. The random walk is a difference stationary series, since the first difference of $Y_{t}$ is stationary:

$$
Y_{t}-Y_{t-1}=(1-L) Y_{t}=\varepsilon_{t}
$$

A difference stationary series is said to be integrated and is denoted as $\mathrm{I}(d)$, where $d$ is the order of integration. The order of integration is the number of unit roots contained in the series or the number of differencing operations taken to make the series stationary. For the random walk above, there is one unit root, so it is an I(1) series. Similarly, a stationary series is I(0). Bierens (1997) anticipated that anticipated regression model involving unit root process may provide spurious regression, because time series data often tend to move in the same direction. Consequently, this may show a higher $R^{2}$ and lower Durbin Watson statistic, which may not indicate the true degree of association among the study variables. For a non-stationary time series $y_{t}$, if one would fit the model $y_{t}=\rho y_{t-1}+\varepsilon_{t}$ and test the null hypothesis $\mathrm{H}_{0}: \rho=1$ in the AR(1) model, the null distribution is non-normal and it follows the Dickey-Fuller distribution. In short, if a time series is generated by a unit root process, the conventional test procedures remain no longer valid. So, it is important to check whether a time series is stationary or not.

\section{VAR Model}

When building a VAR model, the following steps can be used. Firstly, statistic M(i) or the Akaike Information Criterion (AIC) have been used to identify the order, then estimate the specified model by using the least squares method (if there are statistically insignificant parameters, the model should be re-estimated by removing these parameters), and finally use the $Q_{k}(\mathrm{~m})$ statistic of the residuals to check the adequacy of a fitted model. Other characteristics of the residual series, such as conditional heteroscedasticity and outliers, can also be checked.

The time series $Y_{t}$ follows a $\operatorname{VAR}(p)$ model, if it satisfies

$$
Y_{t}=\Phi_{0}+\Phi_{1} Y_{t-1}+\cdots+\Phi_{p} Y_{t-p}+\alpha_{t}, p>0
$$

where, $Y_{t}$ is a vector of the dependent variable; $\Phi_{0}$ is a $k$-dimensional vector; and $\alpha_{t}$ is a sequence of serially 
uncorrelated random vectors with mean zero and covariance matrix $\Sigma$. Covariance matrix $\Sigma$ must be positive definite; otherwise, the dimension of $Y_{t}$ can be reduced. The error term, $\alpha_{t}$ is a multivariate normal and $\Phi_{j}$ are $k \times k$ matrices. Using the back-shift operator $B$, the $\operatorname{VAR}(p)$ model can be written as:

$$
\left(I-\Phi_{1} B-\cdots-\Phi_{P} B^{P}\right) Y_{t}=\Phi_{0}+\alpha_{t}
$$

where, $I$ will be the $k \times k$ identity matrix. In a compact form, it is as follows:

$$
\phi(B) Y_{t}=\Phi_{0}+\alpha_{t}
$$

where, $\Phi(B)=I-\Phi_{1} B-\cdots-\Phi_{P} B^{P}$ is a matrix polynomial, if $Y_{t}$ is weakly stationary, then it reduces to:

$$
\mu=E\left(Y_{t}\right)=\left(\mathrm{I}-\Phi_{1} B-\cdots-\Phi_{P}\right)^{-1} \Phi_{0}=[\Phi(1)]^{-1} \Phi_{0}
$$

Provided that the inverse exists, since determinant of $[\Phi(1)]$ is different from zero.

Let $\widetilde{Y}_{t}=Y_{t}-\mu$, then the $\operatorname{VAR}(p)$ model becomes:

The results can be obtained as:

$$
\tilde{Y}_{t}=\Phi_{1} \tilde{Y}_{t-1}+\cdots+\Phi_{p} \tilde{Y}_{t-p}+\alpha_{t}
$$

$\operatorname{Cov}\left(Y_{t}, \alpha_{t}\right)=\Sigma$, the covariance matrix of $\alpha_{t}$;

$\operatorname{Cov}\left(Y_{t-1}, \alpha_{t}\right)=0$, for $1>0$

$$
\Gamma_{l}=\Phi_{1} \Gamma_{l-1}+\cdots+\Phi_{p} \Gamma_{l-p}, \text { for } 1>0
$$

The equation (5) is a multivariate version of Yule-Walker equation and it is called the moment equation of a $\operatorname{VAR}(p)$ model. The concept of partial autocorrelation function of a univariate series can be generalized to specify the order $p$ of a vector series. Consider the following consecutive VAR models:

$$
\begin{gathered}
Y_{t}=\Phi_{0}+\Phi_{1} Y_{t-1}+\alpha_{t} \\
Y_{t}=\Phi_{0}+\Phi_{1} Y_{t-1}+\Phi_{2} Y_{2}+\alpha_{t} \\
\ldots=\ldots \\
Y_{t}=\Phi_{0}+\Phi_{1} Y_{t-1}+\cdots+\Phi_{p} Y_{t-p}+\alpha_{t} \\
\ldots=\ldots
\end{gathered}
$$

The ordinary least squares (OLS) method is used for estimating parameters of these models. This is called the multivariate linear regression estimation in multivariate statistical analysis (Tsay, 2001). For the equation in equation (5), let, $\widehat{\Phi}_{j}^{(i)}$ be the OLS estimate of $\Phi_{j}$ and $\widehat{\Phi}_{j}^{(i)}$ be the estimate of $\Phi_{0}$, where the superscript (i) is used to denote that the estimates are for a $\operatorname{VAR}(i)$ model. Then, the residual is:

$$
\hat{\alpha}_{t}^{(i)}=Y_{t}-\widehat{\Phi}_{1}^{(i)} Y_{t-1}-\cdots-\widehat{\Phi}_{1}^{(i)} Y_{t-i}
$$

For $i=0$, the residual is defined as $\hat{Y}_{t}^{(0)}=Y_{t}-\bar{Y}$, where $\bar{Y}$ is the sample mean of $Y_{t}$. The residual covariance matrix is defined as:

$$
\widehat{\Sigma}_{i}=\frac{1}{T-2 i-1} \sum_{t=i+1}^{T} \hat{\alpha}_{\mathrm{t}}^{(i)}\left(\widehat{\alpha}_{t}^{(i)}\right)^{\top}
$$

To specify the order $p$, the $i^{\text {th }}$, and $(i-1)^{\text {th }}$ in equation (6) is to test a $\operatorname{VAR}(i)$ model versus a $\operatorname{VAR}(i-1)$ model and test the hypothesis $\mathrm{H}_{0}: \Phi_{l}=0$ versus the alternative hypothesis $\mathrm{H}_{\mathrm{a}}: \Phi_{l} \neq 0$ sequentially for $i=1$, $2, \ldots, I$. The test statistic is:

$$
M(i)=-\left(T-K-i-\frac{3}{2}\right) \ln \left(\frac{\left|\hat{\Sigma}_{i}\right|}{\left|\hat{\Sigma}_{i}-1\right|}\right)
$$


The distribution of $M(i)$ is a chi-squared distribution with $k^{2}$ degrees of freedom. Alternatively AIC can be used to select the order $p$. Assume that $\alpha_{t}$ is multivariate normal and consider the $i^{\text {th }}$ equation, one can estimate the model by the maximum likelihood (ML) method. For AR models, the OLS estimates $\Phi_{0}$ and $\Phi_{j}$ are equivalent to the (conditional) ML estimates. However, there are differences between the estimates of $\Sigma$ and the ML estimates of $\Sigma$ (Tsay, 2001).

$$
\hat{\Sigma}_{i}=\frac{1}{T} \sum_{t=i+1}^{T} \hat{\alpha}_{t}^{(i)}\left(\widehat{\alpha}_{t}^{(i)}\right)^{\top}
$$

The AIC of a $\operatorname{VAR}(i)$ model under the normality assumption is definied as:

$$
\operatorname{AIC}(i)=\ln \left(\left|\tilde{\Sigma}_{i}\right|\right)+\frac{2 K^{2} i}{T}
$$

For a given vector time series, one selects the $\operatorname{AR}$ order $p$ such that $\operatorname{AIC}(p)=\min \{1 \leq i \leq p, \operatorname{AIC}(i)\}$, where $p$ is positive integer. Estimation and model checking both of the OLS method or the maximum likelihood method can be used to estimate parameters of VAR model, since the two methods are asymptotically equivalent. The estimates are asymptotically normal under some regularity conditions, after constructing the model, adequacy of the model should then be checked. The $Q_{k}(m)$ statistic can be applied to the residual series to check the assumption that there are no serial or cross-correlations in the residuals. For a fitted $\operatorname{VAR}(p)$ model, the $Q_{k}(m)$ statistic of the residuals is asymptotically a chi-square distribution with $K^{2}(m-g)$ degrees of freedom, where $g$ is the number of estimated parameters in the AR coefficient matrices (Tsay, 2001).

\section{Structural Analysis by Impulse Response Functions}

The general form $\operatorname{VAR}(p)$ model also has a Wold representation as follows:

$$
Y_{t}=\mu+\theta_{i} \alpha_{i-1}+\theta_{2} \alpha_{t-1}+\cdots
$$

where, $\theta_{s}$ are the $n \times n$ matrices. To interpret the $(i, j)$-th element $\theta_{i j}^{S}$, element of the matrix $\theta_{s}$ as the dynamic multiplier or impulse response:

$$
\frac{\delta y_{i, t+s}}{\delta \alpha_{j, t}}=\frac{\delta y_{i, t}}{\delta \alpha_{j, t-s}}=\theta_{i j}^{S} i, j=1,2, \ldots, n
$$

The condition for the variance of $\alpha_{t}$ equal to $\Sigma$ is a diagonal matrix. If $\Sigma$ is diagonal, it shows that the elements of $\Sigma$ and $\alpha_{t}$ are uncorrelated. One way to make the errors uncorrelated is to estimate the triangular structural $\operatorname{VAR}(p)$ model:

$$
\begin{gathered}
y_{1 t}=c_{1}+\dot{\alpha}_{11} Y_{t-1}+\cdots+\dot{\alpha}_{1 p} Y_{t-p}+\eta_{1 t} \\
y_{2 t}=c_{1}+\beta_{21} Y_{1 t}+\dot{\alpha}_{21} Y_{t-1} \ldots+\dot{\alpha}_{2 p} Y_{t-p}+\eta_{2 t} \\
\ldots=\ldots \\
y_{n t}=c_{1}+\beta_{n 1} Y_{1 t}+\beta_{n, n-1} Y_{n-1, t}+\dot{\alpha}_{n 1} Y_{t-1} \ldots+\dot{\alpha}_{n p} Y_{t-p}+\eta_{n t}
\end{gathered}
$$

The estimated covariance matrix of the error vector $\eta_{t}$ is diagonal. The uncorrelated errors $\eta_{t}$ are referred to as structural errors. The Wold representation of $Y_{t}$ is based on the orthogonal errors $\eta_{t}$ :

where $\Theta_{0}=B^{-1}$.

$$
Y_{t}=\mu+\Theta_{0} \eta_{t}+\Theta_{1} \eta_{t-1}+\Theta_{2} \eta_{t-2}+\cdots
$$

$B$ is the lower triangular matrix of $\beta_{i j}$ in equation (11). The diagonal elements of the $B$ are 1 . The impulse responses to the orthogonal shocks $\eta_{j t}$ are:

$$
\frac{\partial y_{i, t+s}}{\partial \eta_{j, t}}=\frac{\partial y_{i, t}}{\partial \eta_{j, t}-s}=\theta_{i j}^{s} i, j=1,2, \ldots, n
$$


Where, $\theta_{i j}^{s}$ is the $(i, j)^{\text {th }}$ element of $\theta_{s}$. The plot of $\theta_{i j}^{s}$ against $s$ is called the orthogonal impulse response function of $y_{i}$ with respect to $\eta_{j}$.

\section{Structural Analysis by Granger Causality}

In order to investigate the causal relationship among the variables of the system, the linear Granger causality tests should be applied by using the following strategy. Compare the unrestricted models:

$$
\begin{gathered}
\Delta Y_{t}=a_{1}+\sum_{i=1}^{m_{1}} \beta_{1 i} \Delta Y_{t-i}+\sum_{j=1}^{m_{2}} \theta_{1 j} \Delta X_{j-i}+e_{1 t} \\
\Delta X_{t}=a_{2}+\sum_{i=1}^{m_{1}} \beta_{2 i} \Delta Y_{t-i}+\sum_{j=1}^{m_{2}} \theta_{2 j} \Delta Y_{j-i}+e_{2 t}
\end{gathered}
$$

with the restricted models:

$$
\begin{aligned}
\Delta Y_{t} & =a_{1}+\sum_{i=1}^{m_{1}} \beta_{1 i} \Delta Y_{t-i} \\
\Delta X_{t} & =a_{2}+\sum_{i=1}^{m_{1}} \beta_{2 i} \Delta Y_{t-i}
\end{aligned}
$$

where, $\Delta Y_{t}$ and $\Delta X_{t}$ first order forward differences of the variables; $\alpha, \beta$, and $\theta$ are the parameters to be estimated; and $e_{1}$ and $e_{2}$ are standard random errors. The lag $m$ are the optimal lag orders chosen by information criteria. The equations described above are convenient tools for analyzing linear causality relationship among the variables. If $\theta_{1}$ is statistically significant and $\theta_{2}$ is not, it can be said that changes in variable $y$ Granger cause changes in variable $x$ or vice versa. If both of them are statistically significant, there is a bivariate causal relationship among the variables; if both of them are statistically insignificant, neither the changes in variable $y$ nor the changes in variable $x$ have any effect over other variables.

\section{Forecasting}

If the fitted model is adequate, then it can be used to obtain forecasts. For forecasting, same techniques in the univariate analysis can be applied. To produce forecasts and standard deviations of the associated forecast, errors can be done as following. For a $\operatorname{VAR}(p)$ model, the 1-step ahead forecast at the time origin $h$ is:

$$
Y_{h}(1)=\varphi_{0}+\sum_{i=1}^{p} \varphi_{0} Y_{h+1-i}
$$

The associated forecast error is $e_{h}=a_{h+1}$. The covariance matrix of the forecast error is $\Sigma$. If $Y_{t}$ is weakly stationary, then the l-step ahead forecast $Y_{h}(l)$ converges to its mean vector $\mu$ as the forecast horizon increases.

\section{Result and Discussion}

In this paper, the selected indicators of DSE in Bangladesh and the micro economic variables, such as stock trade, invested stock capital, stock volume, current market value, and DSE general indexes for the period of June 2004 to July 2013, have been used as the basis on daily scale. But to get the maximum explorative information and reduction of volatility, the data have been transformed to the monthly scale. Data from June 2004 to July 2013 are used in-sample estimation and from August 2013 to December 2013 are used for the out-of-sample forecasting purposes. The summary statistics of market capital in Taka ( $m n)$, general index, total volume, and total trade of DSE have been shown in Table 1.

The time series plot of invested stock market capital in Taka (mn), DSE general indexes, stock trade, stock volume, and current market value in Taka (mn) for the period of June 2004 to July 2013 has been shown in 
Figure 1. From Figure 1, it has been observed that each study variable rose up in 2010, except stock volume and that there started severe volatility from 2010 to till the end of the day in stock market capital and general indexes, stock trade, stock volume, and current market value data series.

Box and whisker plot has been used to investigate the data series of DSE, of which percents of data are representing maximum frequencies, non-outlier range and which are affected by outliers and extreme values. The box and whisker plot of market capital, general indexes, value, volume, and trade, respectively have been shown in Figures 2, 3, 4, 5, and 6.

Table 1

Summary Statistics of Market Capital, General Index, Total Volume, and Total Trade of DSE

\begin{tabular}{|c|c|c|}
\hline Variable & Statistics & Result \\
\hline \multirow{9}{*}{ Market capital in Taka $(m n)$} & Mean & $1,349,236$ \\
\hline & $5 \%$ trimmed mean & $1,311,896$ \\
\hline & Median & $998,774.6$ \\
\hline & Variance & $1.16 \mathrm{E}+12$ \\
\hline & Std. deviation & $1.08 \mathrm{E}+06$ \\
\hline & Minimum & 1,600 \\
\hline & Maximum & $3,512,212$ \\
\hline & Range & $3,510,612$ \\
\hline & Inter quartile range & $2,172,542$ \\
\hline \multirow{9}{*}{ DSE general index } & Mean & $3,415.11$ \\
\hline & $5 \%$ trimmed mean & $3,298.25$ \\
\hline & Median & $2,907.92$ \\
\hline & Variance & $3.29 \mathrm{E}+06$ \\
\hline & Std. deviation & $1,812.722$ \\
\hline & Minimum & 1,270 \\
\hline & Maximum & 8,340 \\
\hline & Range & 7,070 \\
\hline & Inter quartile range & 2,806 \\
\hline \multirow[t]{9}{*}{ Value in Taka $(m n)$} & Mean & $4,395.16$ \\
\hline & $5 \%$ trimmed mean & $3,745.74$ \\
\hline & Median & $2,800.02$ \\
\hline & Variance & $2.84 \mathrm{E}+07$ \\
\hline & Std. deviation & $5,327.383$ \\
\hline & Minimum & 120 \\
\hline & Maximum & 24,827 \\
\hline & Range & 24,708 \\
\hline & Inter quartile range & 5,515 \\
\hline \multirow{9}{*}{ Total trade } & Mean & $83,572.28$ \\
\hline & $5 \%$ trimmed mean & $77,348.02$ \\
\hline & Median & $69,859.33$ \\
\hline & Variance & $5.27 \mathrm{E}+09$ \\
\hline & Std. deviation & $72,565.02$ \\
\hline & Minimum & 6,427 \\
\hline & Maximum & 316,926 \\
\hline & Range & 310,500 \\
\hline & Inter quartile range & 107,270 \\
\hline
\end{tabular}



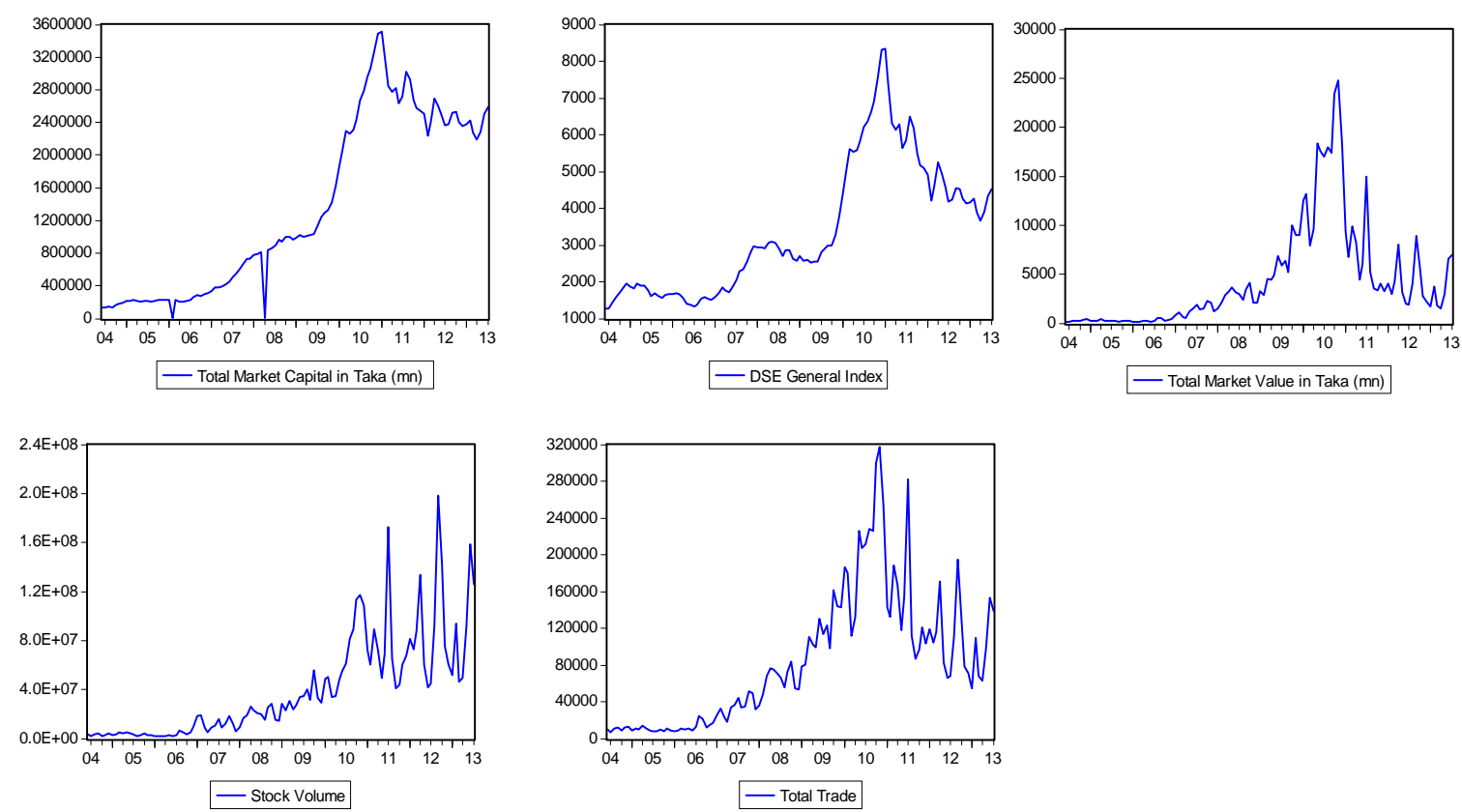

Figure 1. The time series plot of stock market capital, general indexes, stock trade, stock volume, current market value of DSE.

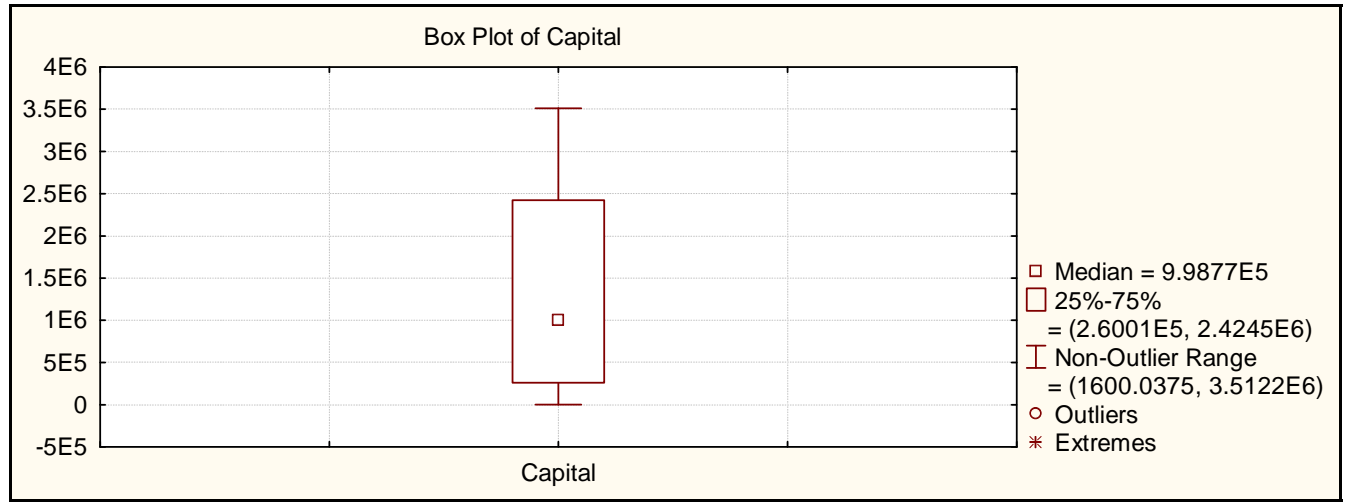

Figure 2. The box and whisker plot of market capital.

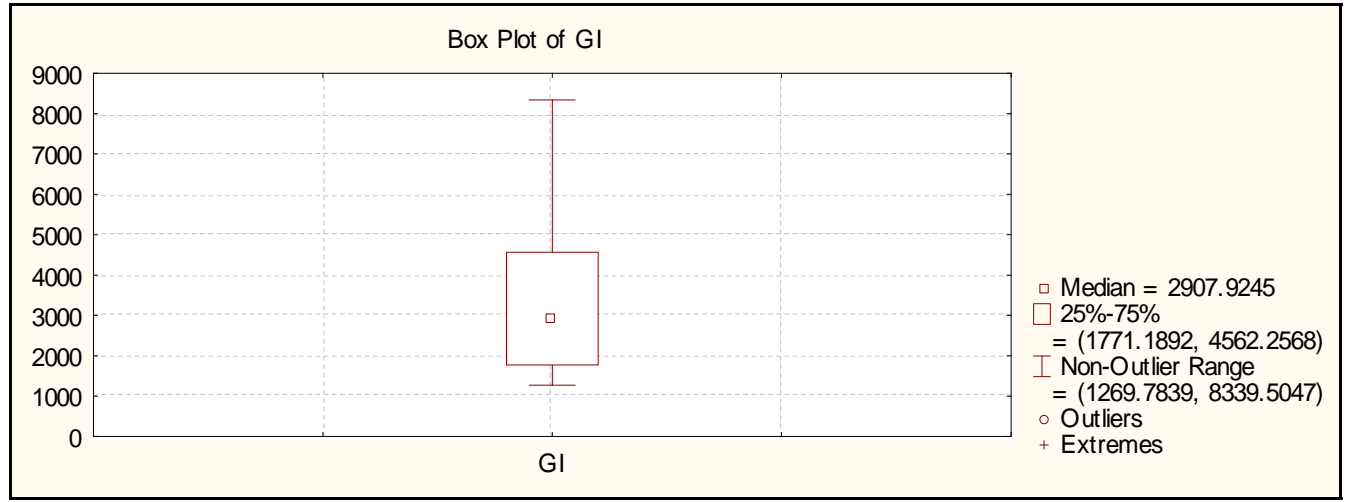

Figure 3. The box and whisker plot of general indexes. 


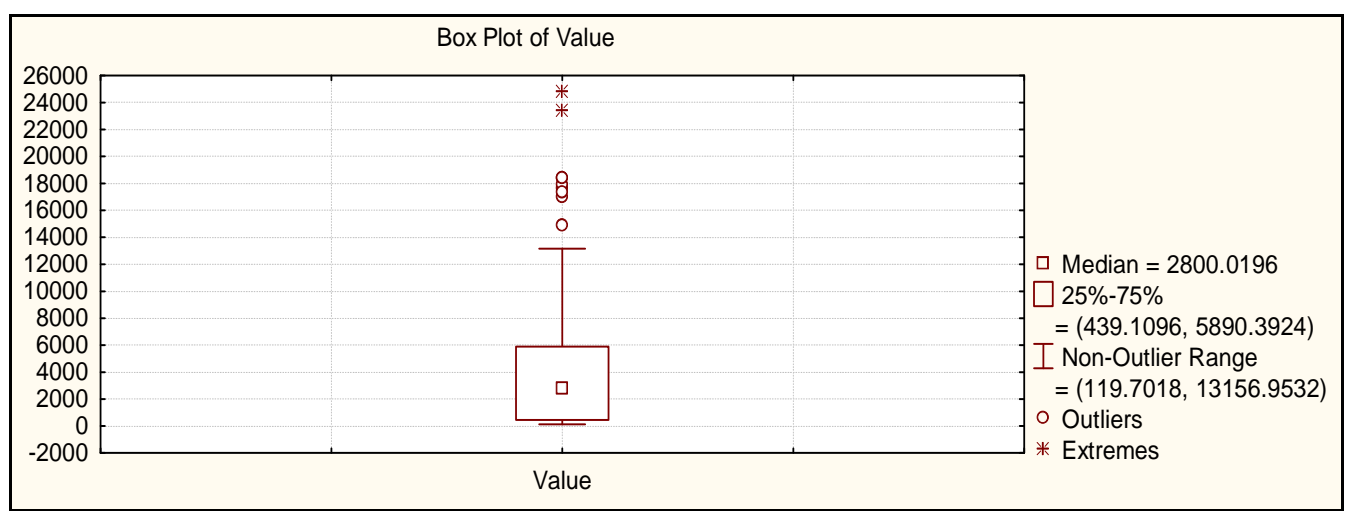

Figure 4. The box and whisker plot of value.

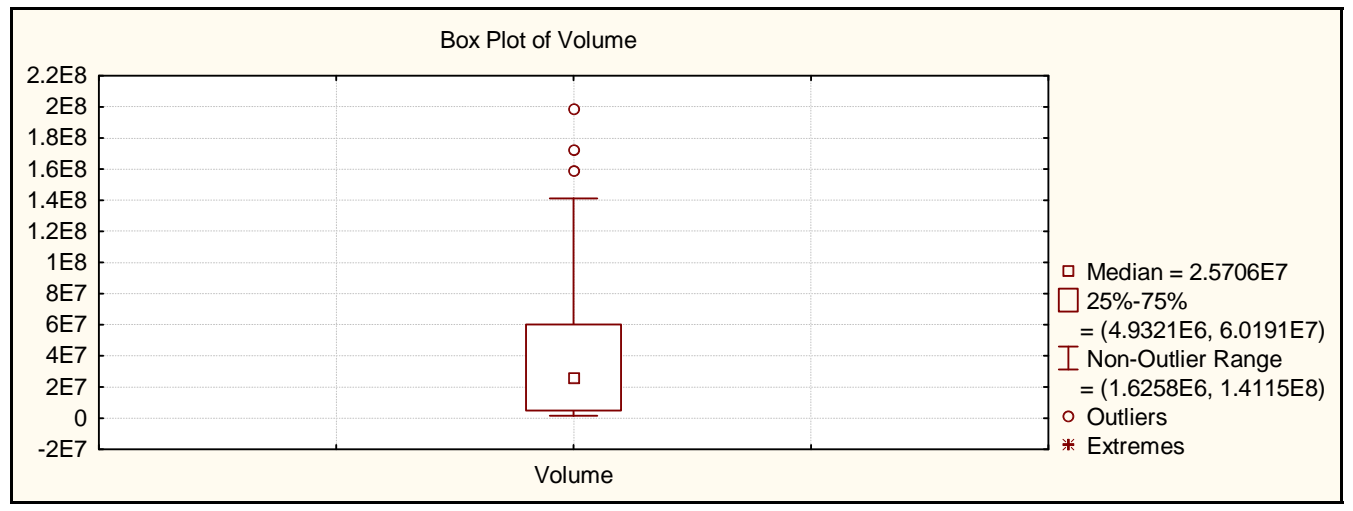

Figure 5. The box and whisker plot of volume.

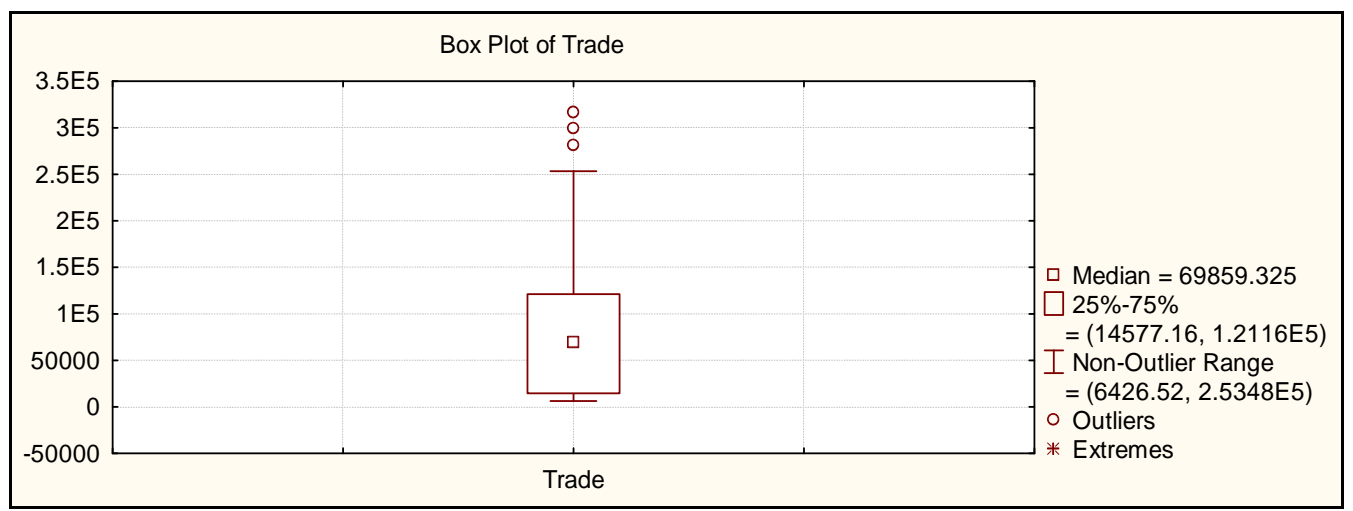

Figure 6. The box and whisker plot of trade.

The box and whisker plot of market capital, general indexes, value, volume, and trade respectively (Figures 2, 3, 4, 5, and 6) reveal that median capital is 9.9877E5, 25\% to 75\% frequency between $2.6001 \mathrm{E} 5$ and 2.4245E6; non-outlier range is $1,600.0375$ to $3.5122 \mathrm{E} 6$ of market capital; and it is not affected by outlier and extreme values. Median general indexes is $2,907.9245,25 \%$ to $75 \%$ frequency between $1,771.1892$ to 4,562.2568; non-outlier range is $1,269.7839$ to $8,339.5047$; and it is not affected by outlier and extreme values also. Median market value is $2,800.0196,25 \%$ to $75 \%$ frequency between 439.1096 and 5,890.3924; non-outlier range is 119.7018 to $13,156.9532$; and it is either affected by outlier and extreme values. Median market volume is $69,859.325,25 \%-75 \%$ frequency between $14,577.16$ and $1.2116 \mathrm{E} 5$; non-outlier range is $6,426.52$ to $2.5348 \mathrm{E} 5$; and it is either affected by outliers but not extreme values. Median market trade is 
$69,859.325,25 \%$ to $75 \%$ frequency between $14,577.16$ and $1.2116 \mathrm{E} 5$; non-outlier range is $6,426.52$ to $2.5348 \mathrm{E} 5$; and it is either affected by outliers but not extreme values.

To check the stationary of the series, unit root test has been tested which has been given in Table 2. ADF, PP test, KPSS, ERS, and NP test have been used.

Table 2

Unit Root Test of Study Variables of DSE

\begin{tabular}{|c|c|c|c|c|c|c|c|}
\hline Variables & $\begin{array}{l}\text { Deterministic } \\
\text { terms }\end{array}$ & Lags & $\begin{array}{l}\mathrm{ADF} \\
(P \text {-value })\end{array}$ & $\begin{array}{l}\text { PP } \\
(P \text {-value })\end{array}$ & $\begin{array}{l}\text { KPSS } \\
\text { [Critical } \\
\text { value] }\end{array}$ & $\begin{array}{l}\text { ERS } \\
\text { [Critical } \\
\text { value]* }\end{array}$ & $\begin{array}{l}\mathrm{NP} \\
{[\text { Critical value }]^{*}}\end{array}$ \\
\hline Market capital & $\begin{array}{l}\text { Constant and } \\
\text { linear trend }\end{array}$ & 2 & $\begin{array}{l}-1.59274 \\
(0.79)\end{array}$ & $\begin{array}{l}-1.74149 \\
(0.73)\end{array}$ & $\begin{array}{l}0.346798 \\
{[0.146]}\end{array}$ & $\begin{array}{l}19.41497 \\
{[5.642]}\end{array}$ & $\begin{array}{l}-4.71836 \\
{[-17.30]}\end{array}$ \\
\hline$\Delta$ (Market capital) & Constant & 1 & $\begin{array}{l}-7.747261 \\
(0.00)^{* *}\end{array}$ & $\begin{array}{l}-11.1975 \\
(0.00)^{* *}\end{array}$ & $\begin{array}{l}0.11879 \\
{[0.463]}\end{array}$ & $\begin{array}{l}0.444132 \\
{[3.1154]}\end{array}$ & $\begin{array}{l}-56.7145 \\
{[-8.100]}\end{array}$ \\
\hline General indexes & $\begin{array}{l}\text { Constant and } \\
\text { linear trend }\end{array}$ & 2 & $\begin{array}{l}-1.22071 \\
(0.90)\end{array}$ & $\begin{array}{l}-1.4494 \\
(-3.451)\end{array}$ & $\begin{array}{l}0.30754 \\
{[0.1460]}\end{array}$ & $\begin{array}{l}20.4768 \\
{[5.642]}\end{array}$ & $\begin{array}{l}-4.34904 \\
{[-17.30]}\end{array}$ \\
\hline$\Delta($ General indexes $)$ & Constant & 1 & $\begin{array}{l}-7.78123 \\
(0.00)^{* *}\end{array}$ & $\begin{array}{l}-6.7700 \\
(0.00)^{* *}\end{array}$ & $\begin{array}{l}0.13408 \\
{[0.4630]}\end{array}$ & $\begin{array}{c}0.27728 \\
{[3.1154]}\end{array}$ & $\begin{array}{l}-85.4106 \\
{[-8.100]}\end{array}$ \\
\hline Value & $\begin{array}{l}\text { Constant and } \\
\text { linear trend }\end{array}$ & 2 & $\begin{array}{l}-1.75874 \\
(0.399)\end{array}$ & $\begin{array}{l}-2.6536 \\
(0.258)\end{array}$ & $\begin{array}{l}0.3679 \\
{[0.146]}\end{array}$ & $\begin{array}{l}11.81244 \\
{[5.642]}\end{array}$ & $\begin{array}{l}-7.60684 \\
{[-17.30]}\end{array}$ \\
\hline$\Delta$ (Value) & Constant & 1 & $\begin{array}{l}-10.74108 \\
(0.00)^{* *}\end{array}$ & $\begin{array}{l}-10.474 \\
(0.00)^{* *}\end{array}$ & $\begin{array}{l}0.034918 \\
{[0.4630]}\end{array}$ & $\begin{array}{l}0.199769 \\
{[3.115]}\end{array}$ & $\begin{array}{l}-121.667 \\
{[-8.100]}\end{array}$ \\
\hline Volume & $\begin{array}{l}\text { Constant and } \\
\text { linear trend }\end{array}$ & 2 & $\begin{array}{l}-5.4066 \\
(0.0001)^{* *}\end{array}$ & $\begin{array}{l}-6.2602 \\
(0.00)^{* *}\end{array}$ & $\begin{array}{l}0.21027 \\
{[0.146]}\end{array}$ & $\begin{array}{l}1.79308 \\
{[5.642]}\end{array}$ & $\begin{array}{l}-46.0939 \\
{[-17.30]}\end{array}$ \\
\hline Trade & $\begin{array}{l}\text { Constant and } \\
\text { linear trend }\end{array}$ & 2 & $\begin{array}{l}-2.235027 \\
(0.465)\end{array}$ & $\begin{array}{l}-3.4555 \\
(0.049)^{* *}\end{array}$ & $\begin{array}{l}0.40364 \\
{[0.146]}\end{array}$ & $\begin{array}{l}9.03074 \\
{[5.642]}\end{array}$ & $\begin{array}{l}-9.96441 \\
{[-17.30]}\end{array}$ \\
\hline$\Delta($ Trade $)$ & Constant & 1 & $\begin{array}{l}-11.67007 \\
(0.00)^{* *}\end{array}$ & $\begin{array}{l}-11.584 \\
(0.00)^{* *}\end{array}$ & $\begin{array}{l}0.0242 \\
{[0.4630]}\end{array}$ & $\begin{array}{l}0.19191 \\
{[3.115]}\end{array}$ & $\begin{array}{l}-127.985 \\
{[-8.100]}\end{array}$ \\
\hline
\end{tabular}

Notes. []* indicates the critical value at $5 \%$ level of significance and ()$^{* *}$ indicates the $P$-value at $5 \%$ level of significance of the respective test statistics.

Table 2 represents the unit root test of market capital, general indexes, value, volume, and trade of DSE. $\mathrm{ADF}, \mathrm{PP}, \mathrm{KPSS}$, ERS, and NP tests results indicate that all variables are non-stationary by not rejecting the null hypothesis of unit-root at 5\% levels of significance and critical values, but they are all stationary after first differencing except volume data of DSE which is normally stationary. Therefore, first order differenced series have been used for all variables except volume series in this analysis.

\section{Empirical Results and Diagnostics}

In this part, the initial aim is to find out the true lag order for the model as Lutkepohl (1991) pointed out that selecting a higher order lag length than the true lag lengths increases the mean square forecast errors of the VAR and selecting a lower order lag length than the true lag lengths usually causes auto correlated errors. As a result, accuracy of forecasts from VAR models highly depends on selecting the true lag lengths. There are several statistical criteria for selecting a lag length. There has been identified a $\operatorname{VAR}(p)$ model for the analysis by using penalty selection criteria, such as AIC and Bayesian Information Criterion (BIC). This analysis reveals the minimum value of AIC and BIC has been got at the lag length of order two than that any other lag lengths of orders. After that a VAR(2) model has been identified, moving forward to model estimation process. The model estimation results from the $\operatorname{VAR}(2)$ model are given in Tables 3, 4, 5, and 6.

After that there has been estimated a suitable VAR(2) model for the variables and this stage of the analysis deals with the diagnostic checking process. There are several methods that control the robustness of the model 
and graphical analysis tools and statistical tests of the residuals have been used for the diagnostic checks. Table 4 exhibits the results of normality $\left(\mathrm{H}_{0}\right.$ : Residuals are multivariate normal) and Table 5 shows heteroscedasticity tests of the residuals. Table 6 and Figure 7 show root of characteristic polynomial of the estimated VAR model which shows the stability condition. Figure 8 indicates the correlations of the estimated residuals of VAR(2) model.

Table 3

Model Estimation Results From VAR(2) Model

\begin{tabular}{|c|c|c|c|c|c|}
\hline & DCAPITAL & DGI & DTRADE & DVALUE & VOLUME \\
\hline DCAPITAL(-1) & -0.570857 & $5.76 \mathrm{E}-06$ & 0.009318 & 0.000680 & 2.851956 \\
\hline SE & $(0.11300)$ & (0.00019) & $(0.02884)$ & $(0.00202)$ & (21.5178) \\
\hline$t$-statistics & {$[-5.05199]^{*}$} & {$[0.02973]^{*}$} & [0.32309]* & {$[0.33700]$} & {$[0.13254]$} \\
\hline DCAPITAL(-2) & -0.227448 & $-2.12 \mathrm{E}-05$ & 0.012570 & 0.001288 & 1.128641 \\
\hline SE & $(0.11183)$ & (0.00019) & $(0.02854)$ & $(0.00200)$ & (21.2953) \\
\hline$t$-statistics & {$[-2.03391]$} & {$[-0.11064]^{*}$} & {$[0.44038]^{*}$} & {$[0.64548]^{*}$} & {$[0.05300]$} \\
\hline DGI(-1) & 290.6657 & 0.370781 & -17.28334 & -1.020391 & $-7,478.008$ \\
\hline SE & (68.9188) & $(0.11814)$ & (17.5910) & $(1.23011)$ & $(13,124.2)$ \\
\hline$t$-statistics & [4.21751] & [3.13860] & {$[-0.98251]$} & {$[-0.82951]$} & {$[-0.56979]$} \\
\hline DGI(-2) & 32.37685 & -0.136865 & -10.16488 & -0.536241 & $-15,827.73$ \\
\hline SE & $(65.7113)$ & $(0.11264)$ & (16.7723) & $(1.17286)$ & $(12,513.4)$ \\
\hline$t$-statistics & {$[0.49271]$} & {$[-1.21509]^{*}$} & {$[-0.60605]$} & {$[-0.45721]$} & {$[-1.26487]$} \\
\hline DTRADE(-1) & -4.342340 & 0.001977 & -0.752422 & -0.060810 & -204.8256 \\
\hline SE & (2.48029) & $(0.00425)$ & $(0.63308)$ & $(0.04427)$ & (472.319) \\
\hline$t$-statistics & {$[-1.75074]$} & {$[0.46500]^{*}$} & {$[-1.18852]$} & {$[-1.37362]^{*}$} & {$[-0.43366]$} \\
\hline DTRADE(-2) & -1.335990 & -0.001847 & -0.044877 & 0.012303 & -247.7935 \\
\hline $\mathrm{SE}$ & $(1.50141)$ & $(0.00257)$ & $(0.38322)$ & $(0.02680)$ & $(285.912)$ \\
\hline$t$-statistics & {$[-0.88982]$} & {$[-0.71773]^{*}$} & {$[-0.11710]$} & {$[0.45911]^{*}$} & {$[-0.86668]$} \\
\hline DVALUE(-1) & 64.86912 & 0.045059 & 7.036459 & 0.733140 & 619.5228 \\
\hline SE & (27.5907) & $(0.04729)$ & $(7.04231)$ & $(0.49246)$ & $(5,254.07)$ \\
\hline$t$-statistics & [2.35113] & {$[0.95275]^{*}$} & [0.99917] & [1.48874] & {$[0.11791]$} \\
\hline DVALUE(-2) & 27.31420 & 0.059777 & -4.865443 & -0.558370 & 769.0154 \\
\hline SE & (23.0874) & $(0.03957)$ & $(5.89289)$ & $(0.41208)$ & $(4,396.52)$ \\
\hline$t$-statistics & [1.18308] & {$[1.51049]^{*}$} & {$[-0.82565]$} & {$[-1.35501]$} & [0.17491] \\
\hline VOLUME(-1) & 0.001878 & $-2.76 \mathrm{E}-06$ & $3.73 \mathrm{E}-05$ & $3.25 \mathrm{E}-06$ & 1.010229 \\
\hline SE & $(0.00138)$ & $(2.4 \mathrm{E}-06)$ & $(0.00035)$ & $(2.5 \mathrm{E}-05)$ & $(0.26289)$ \\
\hline$t$-statistics & {$[1.36047]^{*}$} & {$[-1.16631]^{*}$} & {$[0.10592]^{*}$} & {$[0.13184]^{*}$} & [3.84280] \\
\hline VOLUME(-2) & -0.001963 & $2.25 \mathrm{E}-06$ & -0.000272 & $-1.88 \mathrm{E}-05$ & -0.168293 \\
\hline SE & $(0.00144)$ & $(2.5 \mathrm{E}-06)$ & $(0.00037)$ & $(2.6 \mathrm{E}-05)$ & $(0.27344)$ \\
\hline$t$-statistics & {$[-1.36716]^{*}$} & {$[0.91466]^{*}$} & {$[-0.74192]^{*}$} & {$[-0.73336]^{*}$} & {$[-0.61548]^{*}$} \\
\hline Constant & 33721.33 & 39.46907 & $10,961.83$ & 683.5573 & $7,978,627$ \\
\hline $\mathrm{SE}$ & $(18,195.6)$ & $(31.1896)$ & $(4,644.29)$ & $(324.766)$ & $(3,464,975)$ \\
\hline$t$-statistics & [1.85327] & {$[1.26546]$} & {$[2.36028]$} & [2.10477] & [2.30265] \\
\hline AIC & 26.46909 & 13.73139 & 23.73801 & 18.41743 & 36.96765 \\
\hline BIC & 26.74387 & 14.00617 & 24.01278 & 18.69221 & 37.24243 \\
\hline
\end{tabular}

Notes. Sample (adjusted): 2004:09 2013:07, included observations: 107 after adjusting endpoints; standard errors in () and $t$-statistics in [] and []* indicate that the estimated coefficients are statistically significant at $5 \%$ level of significance. 
Table 4

Normality Test of the Estimated Residuals of VAR(2) Model

\begin{tabular}{lccll}
\hline Component & Skewness & Chi-sq & df & Prob. \\
\hline 1 & -2.022983 & 72.98220 & 1 & 0.0000 \\
2 & 0.229877 & $0.942372^{*}$ & 1 & 0.3317 \\
3 & -0.214868 & $0.823334^{*}$ & 1 & 0.3642 \\
4 & -0.244362 & $1.064879^{*}$ & 1 & 0.3021 \\
5 & 0.613907 & $6.721059^{*}$ & 1 & 0.0095 \\
Joint & & 82.53385 & 5 & 0.0000 \\
\hline Component & Kurtosis & Chi-sq & df & Prob. \\
\hline 1 & 14.72666 & 613.0858 & 1 & 0.0000 \\
2 & 4.272266 & 7.216529 & 1 & 0.0072 \\
3 & 5.947517 & 38.73337 & 1 & 0.0000 \\
4 & 5.232218 & 22.21498 & 1 & 0.0000 \\
5 & 3.460395 & $0.945004^{*}$ & 1 & 0.3310 \\
\hline Joint & & 682.1957 & 5 & 0.0000 \\
\hline Component & Jarque-Bera & df & Prob. & \\
1 & 686.0680 & 2 & 0.0000 & \\
2 & 8.158901 & 2 & 0.0169 & \\
3 & 39.55670 & 2 & 0.0000 & \\
4 & 23.27986 & 2 & 0.0000 & 0.0216 \\
5 & 7.666063 & 2 & 0.0000 & \\
\hline Joint & 764.7295 & 10 & & \\
\hline & & $20 p$ & 1 & \\
\hline
\end{tabular}

Note. VAR residual normality tests [Cholesky (Lutkepohl)].

From Table 4, it is observed that the estimated residuals of VAR(2) model have come from multivariate normal distribution and statistically significant at $5 \%$ level of significance except $(*)$ marked statistics.

Table 5

VAR Residual Heteroscedasticity Tests

\begin{tabular}{lll}
\hline Joint test & & \\
\hline Chi-sq & df & Prob. \\
486.1293 & 300 & 0.0000 \\
\hline
\end{tabular}

Note. VAR residual heteroscedasticity tests: no cross terms (only levels and square).

From Table 5, it can be seen that the estimated results are not affected by heteroscedasticity problem and calculated value of Chi-sq is 486.1293 with $300 \mathrm{df}$ and statistically significant at $5 \%$ level of significant.

Table 6 and Figure 3 represent that no root lies outside the unit circle. Therefore, VAR(2) model satisfies the stability condition.

From Figure 8, it can be seen that most of the spikes of the estimated residuals from VAR(2) model lie within the three sigma confidence interval. Therefore, it might be free from outliers and extreme values. In order to see the dynamics of the variables, there have been applied impulse response analysis and Granger causality tests. Figure 9 shows the combined graph of the impulse responses of each variable of the estimated VAR(2) model. As can be seen from the graph, stock capital has immediate effect on general indexes, trade, 
current value, and volume. Similarly, general indexes, trade, current value, current volume, and stock capital have immediate effect on all the others except volume series of DSE. Stock volume has only direct impact on general indexes of DSE. Table 7 represents the Granger causality test of each of the variables of DSE under study.

Table 6

Stability Test of Roots of Characteristic Polynomial of Estimated VAR Model

\begin{tabular}{ll}
\hline Root & Modulus \\
\hline 0.925801 & 0.925801 \\
$0.110128-0.628654 \mathrm{i}$ & 0.638227 \\
$0.110128+0.628654 \mathrm{i}$ & 0.638227 \\
$-0.081331-0.488793 \mathrm{i}$ & 0.495513 \\
$-0.081331+0.488793 \mathrm{i}$ & 0.495513 \\
$-0.288446+0.391117 \mathrm{i}$ & 0.485977 \\
$-0.288446-0.391117 \mathrm{i}$ & 0.485977 \\
$0.194636-0.325181 \mathrm{i}$ & 0.378980 \\
$0.194636+0.325181 \mathrm{i}$ & 0.378980 \\
-0.004904 & 0.004904 \\
\hline
\end{tabular}

Notes. Endogenous variables: D (capital), D (GI), D (trade), D (value), and volume; D represents I(1); exogenous variables: constant; and lag specification: 1 and 2.

Inverse Roots of AR Characteristic Polynomial

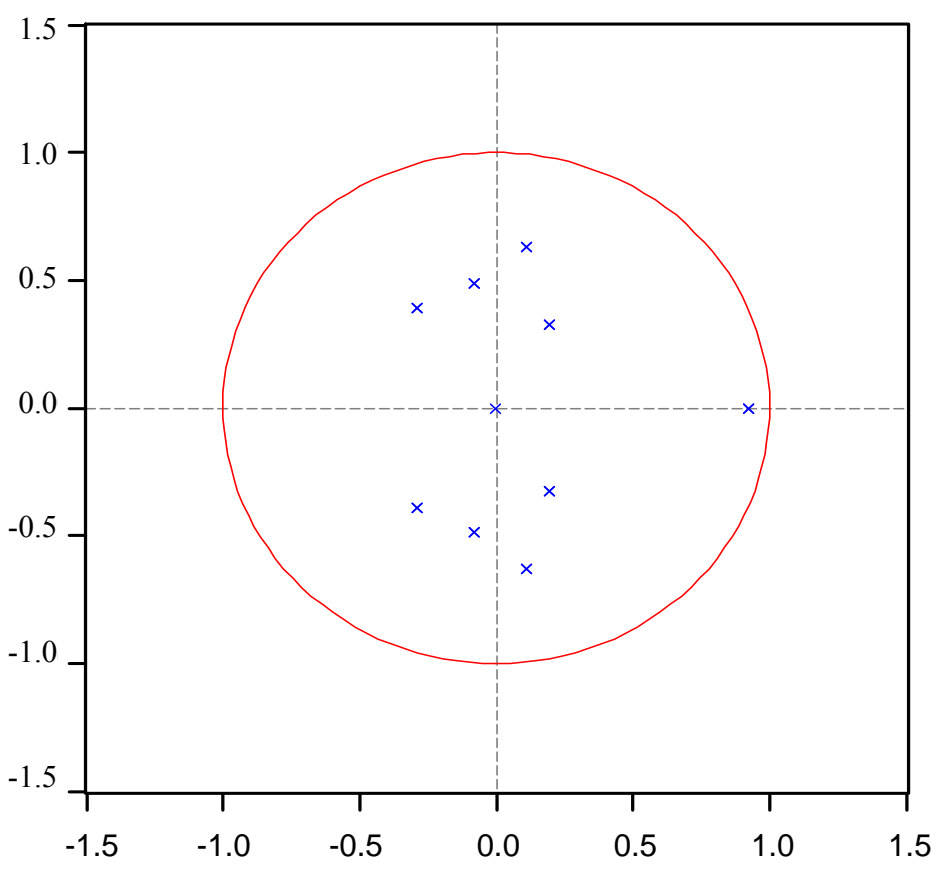

Figure 7. Inverse roots of AR characteristic polynomial of the estimated VAR(2) model. 


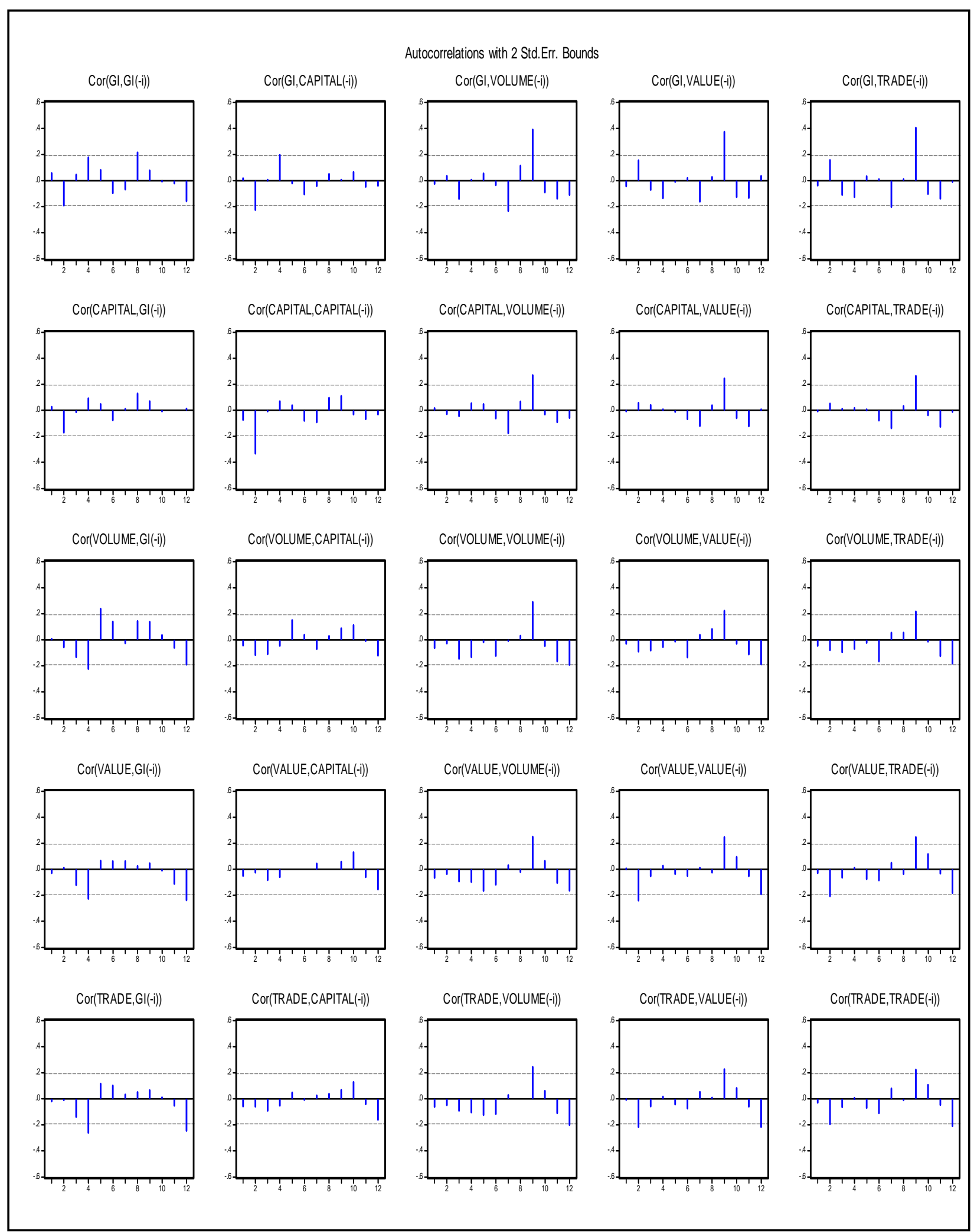

Figure 8. Correlations of the estimated residuals of VAR(2) model. 


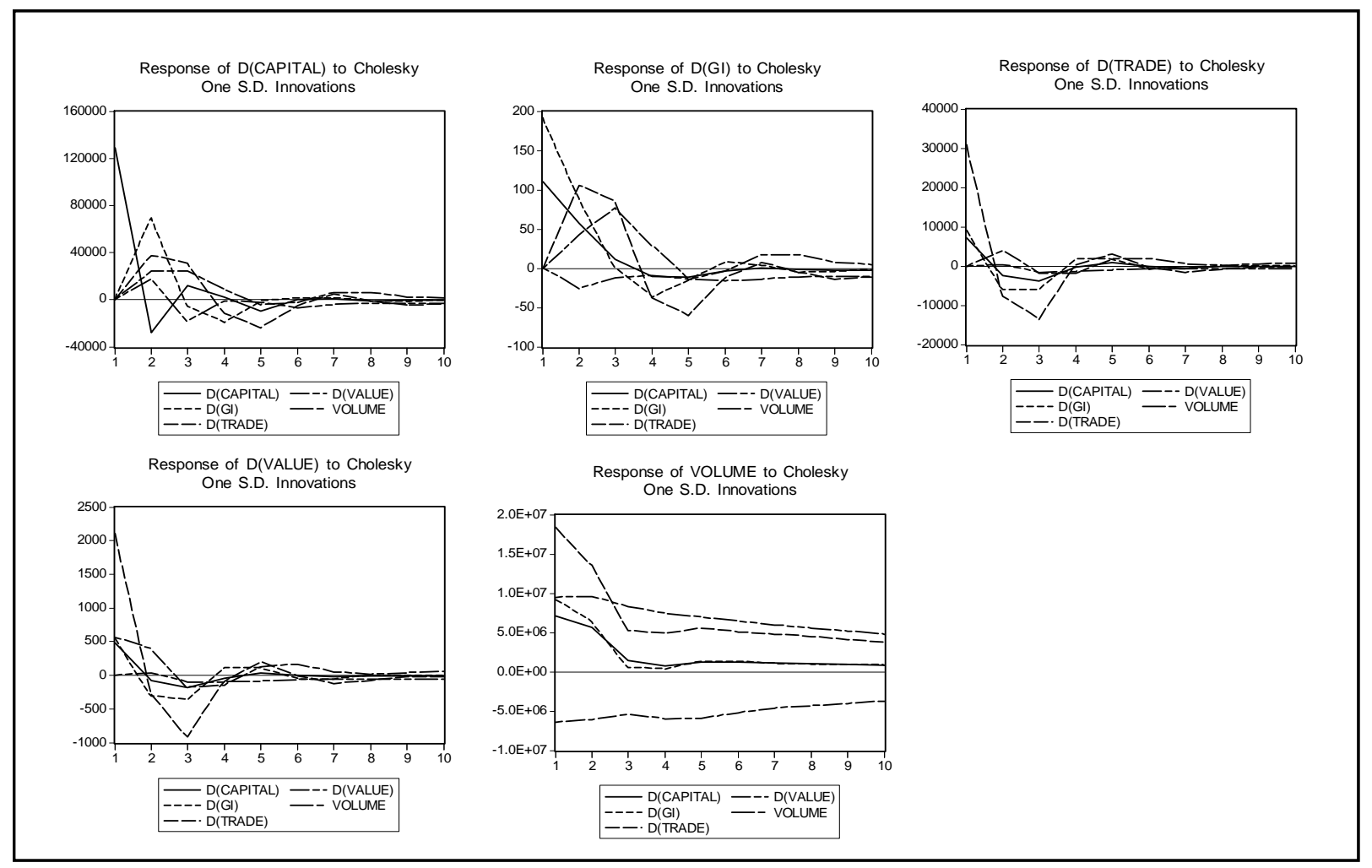

Figure 9. The combined graph of the impulse responses of the estimated VAR(2) model.

Table 7

Pair Wise Granger Causality Tests

\begin{tabular}{llll}
\hline Null hypothesis & Obs & $F$-statistic & Probability \\
\hline GI does not Granger Cause CAPITAL & 108 & $14.4312^{*}$ & $3.0 \mathrm{E}-06$ \\
CAPITAL does not Granger Cause GI & & 0.99219 & 0.37428 \\
\hline TRADE does not Granger Cause CAPITAL & 108 & $19.2568^{*}$ & $7.9 \mathrm{E}-08$ \\
CAPITAL does not Granger Cause TRADE & & 3.90001 & 0.02330 \\
\hline VALUE does not Granger Cause CAPITAL & 108 & $17.3154^{*}$ & $3.3 \mathrm{E}-07$ \\
CAPITAL does not Granger Cause VALUE & & 1.13685 & 0.32482 \\
\hline VOLUME does not Granger Cause CAPITAL & 108 & $5.40554^{*}$ & 0.00586 \\
CAPITAL does not Granger Cause VOLUME & & $19.6973^{*}$ & $5.7 \mathrm{E}-08$ \\
\hline TRADE does not Granger Cause GI & 108 & $31.3317^{*}$ & $2.3 \mathrm{E}-11$ \\
GI does not Granger Cause TRADE & & $4.80681^{*}$ & 0.01010 \\
\hline VALUE does not Granger Cause GI & 108 & $32.6324^{*}$ & $1.1 \mathrm{E}-11$ \\
GI does not Granger Cause VALUE & & 2.27186 & 0.10826 \\
\hline VOLUME does not Granger Cause GI & 108 & $6.17087^{*}$ & 0.00294 \\
GI does not Granger Cause VOLUME & & $9.15604^{*}$ & 0.00022 \\
\hline VALUE does not Granger Cause TRADE & 108 & 0.39541 & 0.67442 \\
TRADE does not Granger Cause VALUE & 108 & 0.17806 & 0.83715 \\
\hline VOLUME does not Granger Cause TRADE & & 2.51300 & 0.08598 \\
TRADE does not Granger Cause VOLUME & 108 & 1.91118 & 0.156771 \\
\hline VOLUME does not Granger Cause VALUE & & 0.52185 & 0.59498 \\
VALUE does not Granger Cause VOLUME & &
\end{tabular}

Note. Lags: 2 and $(*)$ marked that $F$-statistics are statistically significant at $5 \%$ level of significance. 
Table 7 shows the Granger causality test results. The test results indicate that there is a bivariate causal relationship among the variables marked as $\left(^{*}\right)$ by rejecting the null hypothesis of no Granger causality. After that, the model for in-sample analysis has been estimated and checked. This stage deals with the out-sample forecasting performance analysis. Data from June 2004 to July 2013 are used for in-sample estimation and from August 2013 to December 2013 are used for the out-sample forecasting purposes and compare the results of the $\operatorname{VAR}(2)$ model with the univariate models $\operatorname{ARIMA}(1,1,1)$, each of which is chosen for each variable by penalty selection criteria.

Table 8

RMSE Statistics for Forecast Performance for Out-Samples

\begin{tabular}{lll}
\hline Variable & VAR $(2)$ & ARIMA $(1,1,1)$ \\
\hline$\Delta$ (Market capital) & 34.71275 & 38.80718 \\
$\Delta$ (General indexes) & 1.437179 & 1.53407 \\
$\Delta$ (Value) & 17.53741 & 4.769211 \\
Volume & 4.637578 & 523.2658 \\
$\Delta$ (Trade) & 479.0224 & 18.09644 \\
\hline
\end{tabular}

From Table 8, it is observed that the RMSE statistics for forecast performance for out-samples of VAR(2) model are minimum from ARIMA $(1,1,1)$ models for market capital, general indexes, and volume data series of DSE. Therefore, the forecasting performance of $\operatorname{VAR}(2)$ model is quietly reasonable than from ARIMA $(1,1$, 1) models.

\section{Conclusions}

In this paper, authors have explored a multivariate time series model for DSE. VAR(2) model has been applied in modeling and forecasting the market capital, general indexes, volume, trade, and current value for the period from August 2013 to December 2013. It has been chosen as the best candidate model for the variables in sample period. Model estimation results, impulse response analysis, and Granger causality tests indicate that while VAR(2) model is a satisfactory model for market capital, general indexes, and volume data series of DSE, it is not a suitable one for the stock market dynamics of value and trade data series. Further study on continuous-time stochastic models should be better for modeling the dynamics of DSE. Also, heteroscedasticty tests show that volatility of the series is not constant. An extended study on multivariate GARCH models would be better for modeling the series for the sample period.

\section{References}

Ainul, I., \& Khaled, M. (2005). Tests of weak-form efficiency of the Dhaka stock exchange. Journal of Business Finance \& Accounting, 32(7-8), 1613-1624.

Bierens, H. J. (1997). Testing the unit root with drift hypothesis against nonlinear trend stationarity with an application to the U.S. price level and interest rate. Journal of Econometrics, 81, 29-64.

Campbell, J., Lo, A., \& MacKinlay, C. (1997). The econometrics of financial markets. Princeton: Princeton University Press.

Chowdhury, S. S. H., Sadique, M. S., \& Rahman, M. A. (2001). Capital market seasonality: The case of Dhaka stock exchange (DSE) returns. South Asian Journal of Management, 8, 1-8.

Culbertson, K. (1996). Quantitative financial economics: Stocks, bonds and foreign exchange. New York: John Wiley \& Sons.

Dickey, D. A., \& Fuller, W. A. (1979). Distribution of the estimators for autoregressive time series with a unit root. Journal of the American Statistical Association, 74, 427-431.

Elliott, G., Rothenberg, T. J., \& Stock, J. H. (1996). Efficient tests for an autoregressive unit root. Econometrica, 64, 813-836. 
Hamilton, J. D. (1994a). Time series analysis. Princeton: Princeton University Press.

Hamilton, J. D. (1994b). State space models. In R. F. Engle and D. L. McFadden (Eds.), Handbook of econometrics. Amsterdam: Elsevier.

Hassan, M. K., \& Chowdhury, S. S. H. (2008). Efficiency of Bangladesh stock market: Evidence from monthly index and individual firm data. Applied Financial Economics, 18(9), 749-758.

Islam, M. N. (2011). Problems and prospects of stock market in Bangladesh. Economic Research, 12, 81.

Kader, A. A., \& Rahman, M. A. (2005). Testing the weak-form efficiency of an emerging market: Evidence from the Dhaka stock exchange of Bangladesh. AIUB Journal, 4(2), 109-132.

Khababa, N. (1998). Behavior of stock prices in the Saudi Arabian financial market: Empirical research findings. Journal of Financial Management \& Analysis, 11(1), 48-55.

Koutmos, G., Negakis, C., \& Theodossiou, P. (1993). Stochastic behavior of the Athens stock exchange. Applied Financial Economics, 3, 119-126.

Kwiatkowski, D., Phillips, P. C. B., Schmidt, P., \& Shin, Y. (1992). Testing the null hypothesis of stationary against the alternative of a unit root. Journal of Econometrics, 54, 159-178.

Lutkepohl, H. (1991). Introduction to multiple time series analysis. Berlin: Springer-Verlag.

Lutkepohl, H. (1999). Vector autoregressions (Unpublished manuscript, Institutfür Statistik und Ökonometrie, Humboldt-Universitat zu, Berlin).

Mills, T. C. (1999). The econometric modeling of financial time series (2nd ed.). Cambridge: Cambridge University Press.

Mobarek, A., Mollah, S. A., \& Bhuyan, R. (2008). Market efficiency in emerging stock market: Evidence from Bangladesh. Journal of Emerging Market Finance, 7(1), 17-41.

Ng, S., \& Perron, P. (2001). Lag length selection and the construction of unit root tests with good size and power. Econometrica, 69(6), 1519-1554.

Phillips, P. C. B., \& Perron, P. (1988). Testing for a unit root in time series regression. Biometrika, 75, 335-346.

Sadique, S., \& Chowdhury, S. S. H. (2002). Serial dependence in the Dhaka stock exchange returns: An empirical study. Journal of Bangladesh Studies, 4, 47-57.

Sims, C. A. (1980). Macroeconomics and reality. Econometrica, 48, 1-48.

Tsay, R. S. (2001). Analysis of financial time series. Berlin: Springer-Verlag.

Uddin, M. G. S., \& Alam, M. M. (2007). The impacts of interest rate on stock market: Evidence from Dhaka stock exchange. South Asian Journal of Management and Sciences, 1(2), 123-132.

Uddin, M. G. S., \& Khoda, N. M. A. K. (2009). An empirical examination of random walk hypothesis for Dhaka stock exchange: Evidence from pharmaceutical sector of Bangladesh. International Research Journal of Finance and Economics, 33, 87-100.

Waggoner, D. F., \& Zha, T. (1999). Conditional forecasts in dynamic multivariate models. Review of Economics and Statistics, 81(4), 639-651.

Watson, M. (1994). Vector autoregressions and cointegration. In R. F. Engle and D. MacFadden (Eds.), Handbook of econometrics. Amsterdam: Elsevier Science Ltd. 